\title{
Anti-factor $\mathrm{H}$ antibody associated hemolytic uremic syndrome following SARS-CoV-2 infection
}

\author{
Priyanka Khandelwal ${ }^{1}$ Sudarsan Krishnasamy ${ }^{1} \cdot$ Srinivasavaradan Govindarajan $^{1} \cdot$ Manish Kumar ${ }^{2} \cdot$ Binata Marik $^{1}$. \\ Aditi Sinha ${ }^{1}$. Pankaj Hari ${ }^{1}$. Arvind Bagga ${ }^{1}$ (i)
}

Received: 7 September 2021 / Revised: 20 October 2021 / Accepted: 15 November 2021 / Published online: 28 January 2022

(c) The Author(s), under exclusive licence to International Pediatric Nephrology Association 2022

\begin{abstract}
Background The pathogenesis of autoantibody generation in anti-factor $\mathrm{H}(\mathrm{FH})$ antibody associated atypical hemolytic uremic syndrome (aHUS) is unknown and is perhaps triggered by an infectious or environmental agent. We observed an unusual increase of patients with anti-FH antibody associated aHUS coinciding with the second pandemic wave in New Delhi and suspected that SARS-CoV-2 infection might be a potential trigger.

Methods We screened for SARS-CoV-2 infection using reverse transcriptase polymerase chain reaction (RT-PCR) and serology in 13 consecutive patients with anti-FH antibody associated aHUS during the past year in New Delhi.

Results We report 5 patients, 4-13 years old, who presented with a febrile illness without respiratory symptoms during the second pandemic wave. Of these, 3 patients presented with a relapse 25-85 months following the initial episode of aHUS. SARS-CoV-2 was detected by RT-PCR in 1 patient and by serology in 4 patients (median titer 47.1 cut-off index). Patients had high titers of anti-FH antibodies (median 2,300 AU/ml). Genetic studies, done in 3 of the 5 patients, showed homozygous CFHRI deletion without other significant genetic abnormalities. Specific management comprised plasma exchanges and oral prednisolone, combined with either cyclophosphamide or mycophenolate mofetil. At median followup of 3.3 months, the estimated glomerular filtration rate in 4 patients ranged from 62 to $110 \mathrm{ml} / \mathrm{min} / 1.73 \mathrm{~m}^{2}$; one patient was dialysis-dependent.

Conclusion Increased vigilance is required during the pandemic, especially in patients with anti-FH associated aHUS, who might relapse despite quiescent disease for a prolonged period.
\end{abstract}

Keywords Coronavirus 19 - Factor H · Complement factor H related protein · Alternative complement pathway · Thrombotic microangiopathy

\section{Introduction}

Atypical hemolytic uremic syndrome (aHUS), a form of thrombotic microangiopathy, is characterized by dysregulation of the alternative complement pathway. About $30-60 \%$ of patients with aHUS either have pathogenic variants in genes encoding complement regulatory proteins

Arvind Bagga

arvindbagga@hotmail.com

1 Division of Nephrology, Department of Pediatrics, ICMR Center for Advanced Research in Nephrology, All India Institute of Medical Sciences, Ansari Nagar, New Delhi 110029, India

2 Department of Pediatrics, Chacha Nehru Bal Chikitsalaya, New Delhi, India or autoantibodies to factor $\mathrm{H}(\mathrm{FH})$ [1]. Anti-FH antibody associated aHUS is a distinct subgroup of aHUS, occurring during school-going age and associated with an 84-kb homozygous deletion of the CFHR1 gene in most patients $[1,2]$. While this condition comprises more than $50 \%$ of cases of aHUS in Indian children [3], the pathogenesis of antibody generation and the reasons for it being limited to the school age are unclear. The occurrence of a febrile, gastrointestinal, or respiratory prodrome in 50-70\% patients with anti-FH associated aHUS $[2,4]$ and $~ 30 \%$ of other forms of aHUS has led to the hypothesis that additional infectious or environmental trigger(s) are necessary "second-hits" for the disease to manifest. A previous study from this center showed multiple gastrointestinal pathogens in 35 patients, chiefly with anti-FH associated aHUS [5]. 
Recently, aHUS has been reported to be triggered by infection with severe acute respiratory syndrome coronavirus 2 (SARS-CoV-2) [6-8]. Severe coronavirus disease (COVID-19) causes widespread microvascular damage including thrombotic microangiopathy, driven by inflammation, cytokine storm, and dysregulated complement activation [9]. Circulating biomarkers of alternative and terminal complement pathway activation, including $\mathrm{C} 5 \mathrm{a}$ and soluble C5b-9, are shown to correlate with the severity of SARSCoV-2 infection in children [10] and adults [11-13]. While several autoimmune diseases such as immune thrombocytopenic purpura, thrombotic thrombocytopenic purpura, autoimmune hemolytic anemia, and systemic lupus erythematosus have been associated with SARS-CoV-2 infection [14], the association of anti-FH associated aHUS has rarely been reported. In a recent report of 5 adults with SARS-CoV-2 triggered aHUS, genetic variations were found in all patients tested; additionally, anti-FH autoantibodies were detected with pathogenic $\mathrm{CFI}$ variant and $\mathrm{CFH}-\mathrm{H} 3$ at-risk polymorphism in 2 patients [15].

India, one of the countries highly affected by COVID19 , has had the pandemic unfold in two waves, one in September-October 2020 and another in April-June 2021. We observed an unusual increase in patients with anti-FH antibody associated aHUS coinciding with the second wave of the pandemic in New Delhi and report 5 patients with the disease that was triggered by mild SARS-CoV-2 infection.

\section{Methods}

We screened for SARS-CoV-2 infection in consecutive patients younger than 18 years with anti-FH antibody associated aHUS, admitted at any pediatric nephrology center in Delhi between August 2020 and August 2021. Anti-FH antibody associated aHUS was diagnosed due to the presence of microangiopathic hemolytic anemia (hemoglobin $<10 \mathrm{~g} / \mathrm{dL}$, schistocytes $\geq 2 \%$, lactate dehydrogenase $>450 \mathrm{U} / \mathrm{l}$ ), thrombocytopenia (platelets $<150,000 / \mu \mathrm{l}$ ), acute kidney injury, and anti-FH antibody titer $>150 \mathrm{AU} / \mathrm{ml}$ [16]. Patients with septicemia, disseminated intravascular coagulation, thrombotic microangiopathy secondary to medications, systemic lupus, tropical infections, and HIV infection were excluded. Anti-FH antibodies were tested in a 1:50 dilution of plasma samples by manual ELISA; titer $>150 \mathrm{AU} / \mathrm{ml}$ were abnormal [3]. Soluble terminal complement complex (sC5b-9) was measured by ELISA using the MicroVue kit (QuidelCorp, San Diego, CA). Testing for SARS-CoV-2 infection was performed on nasal and oropharyngeal swabs using reverse transcriptase polymerase chain reaction (RT-PCR). Serum samples from patients with negative RT-PCR were tested for SARS-CoV-2 IgG and IgM antibodies by Centers for Disease Control approved double-antigen sandwich electrochemiluminescence immunoassay (Elecsys, Roche Diagnostics, Germany). Clinical exome sequencing and multiplex ligation dependent probe amplification for variants in complement regulatory genes and copy number variations in CFHR1-5, respectively, were done in patients with relapsing illness [17].

Kidney replacement therapy was provided, when required. Upon diagnosis of a primary episode of aHUS or its relapse, membrane filtration-based plasma exchanges (PEX) were promptly initiated, with $60 \mathrm{ml} / \mathrm{kg}$ plasma exchanged with fresh frozen plasma. PEX was performed daily until hematological remission, followed by tapering over 2 weeks [16]. Immunosuppression was initiated following confirmation of positive anti-FH antibody titer and comprised oral prednisolone $(1 \mathrm{mg} / \mathrm{kg} / \mathrm{day}$ for 4 weeks followed by tapering) and intravenous (IV) cyclophosphamide $\left(500 \mathrm{mg} / \mathrm{m}^{2}\right.$ every 4 weeks for 5 doses); patients with relapse received oral mycophenolate mofetil $\left(1,000 \mathrm{mg} / \mathrm{m}^{2}\right)$ instead of cyclophosphamide. Hematological remission was defined as platelet count $>150,000 / \mathrm{mm}^{3}$ and the absence of microangiopathic anemia [16]. Disease relapse was considered when there was a new episode of illness after being in remission for $\geq 2$ weeks [16]. Outcomes were assessed in terms of estimated glomerular filtration rate (eGFR), hypertension and dipstick proteinuria.

\section{Results}

We screened for SARS-CoV-2 infection by RT-PCR and serology in 13 patients (10 boys), with median age of 8 years (range 4-13 years) diagnosed with anti-FH associated aHUS in the last year. Median anti-FH antibody titer was 2,300 (range 646-13,304) AU/ml. While 8 patients presented between August 2020 and March 2021 before the second wave of the pandemic, 5 presented within 6 weeks of the peak of the second wave during June-July 2021 (Fig. 1). The former patients showed negative RT-PCR and undetectable SARS-CoV-2 antibodies (median 0.03, range 0.03-0.08; normal $<1.0$ cut-off index, COI). The latter 5 patients showed high titers of SARS-CoV-2 antibodies (median 47.1, range 10-135.8 COI). SARS-CoV-2 was detected by RT-PCR in 1 patient who had normal chest radiograph and history of contact with symptomatic COVID-19 in a family member. (Table 1 describes the clinical and biochemical features of the 5 patients.) While patients \#1 and \#5 had new onset illness, patients \#2-4 presented with a relapse of aHUS, 25-85 months following the initial episode.

All 5 patients had a febrile illness occurring 8-21 days (median 10 days) preceding hospital admission that lasted for 3-5 days. History of cough, sore throat, breathlessness, diarrhea, anosmia, and ageusia were absent. At admission, chief complaints were abdominal pain, vomiting, and 


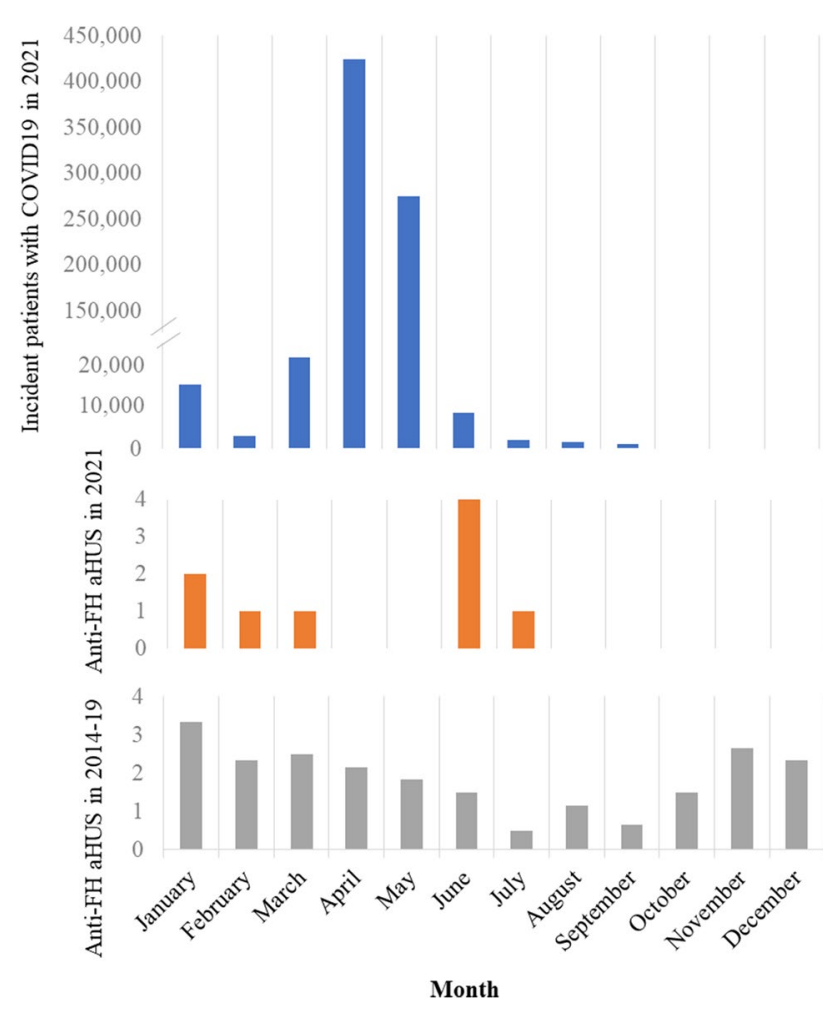

Fig. 1 Mean number of patients with anti-factor $\mathrm{H}$ associated atypical HUS (aHUS) presenting per month in New Delhi between 2014 and 2019 (lower panel) and in 2021 (middle panel) is shown in relation to monthly incident cases of COVID-19 in Delhi during the second wave of the pandemic (upper panel). The peak number of patients affected by COVID-19 in Delhi was 28,395 per day during the last week of April 2021

oliguria, with examination showing pallor, hypertension, and edema. The diagnosis of HUS was based on anemia with median hemoglobin level of 5.8 (range 3.5-8.3) g/dl, 2-6\% schistocytes in the peripheral smear, thrombocytopenia with median platelet counts of $55,000(32,000-120,000) / \mu 1$, and elevated creatinine $3.1(1.3-7.6) \mathrm{mg} / \mathrm{dl}$ requiring dialysis in all patients. Direct Coombs test was negative, and there was no evidence of sepsis and disseminated intravascular coagulation. Parasitic forms of Plasmodia spp. were not detected on peripheral blood or by quantitative buffy coat assay. Serologies for dengue, leptospira and scrub typhus, and antinuclear antibody and antineutrophil cytoplasmic antibodies were negative. Complement evaluation showed low levels of serum C3 in all patients (median 64, range 48-84 mg/ dl) (Table 1). Patients had high titers of anti-FH antibodies (median 2,300, range 1,580-13,304 AU/ml). Autoantibody titers at relapse in patients \#2-4 ranged from 1,580 to 2,300 $\mathrm{AU} / \mathrm{ml}$; serial titer during remission estimated 3 months to 2 years prior to relapse had ranged between 53 and $422 \mathrm{AU} /$ $\mathrm{ml}$. Multiplex ligation-dependent probe amplification, done in the 3 patients with relapse, showed homozygous deletion of CFHR1 and CFHR3. Exome sequencing did not show significant variations in $C F H, C F I, C F B, C 3, C D 46, D G K E$, THBD, ADAMTS13, and $P L G$ in these patients (Table 1).

Following the diagnosis of HUS, daily plasma exchanges using fresh frozen plasma were initiated. Following hematological remission at a median of 5 (range 5-7) days, the exchanges were tapered and stopped at median 15 (range 15-20) days. Immunosuppression with oral prednisolone $(1 \mathrm{mg} / \mathrm{kg} /$ day) was initiated upon detection of anti-FH antibodies, and after a week in patient \#2 following demonstration of undetectable SARS-CoV-2 by RT-PCR. Induction immunosuppression with pulse IV cyclophosphamide $\left(500 \mathrm{mg} / \mathrm{m}^{2}\right)$ was initiated in patients \#1 and \#5. The initial episode of anti-FH associated aHUS in patients \#2-4 was previously treated with 6 pulses of IV cyclophosphamide and prednisolone for a year, followed by mycophenolate mofetil for 2 years. During the current relapse, these patients were again treated with mycophenolate mofetil $(1,000 \mathrm{mg} /$ $\mathrm{m}^{2} /$ day) and tapering doses of prednisolone.

Kidney recovery occurred following hemodialysis for 2-7 days in patients \#1-4; patient \#5 was dialysis-dependent at 12 weeks follow-up. After median follow-up of 4.3 (range 2.8-4.7) months, eGFR ranged from 47 to $134 \mathrm{ml} / \mathrm{min} / 1.73$ $\mathrm{m}^{2}$ in patients \#1-4, with variable degrees of hypertension and proteinuria (Table 1). Anti-FH antibody titers have declined to a median level of 519 (range 152-1,013) AU/ml at last follow-up in all patients.

\section{Discussion}

We report 5 patients with anti-FH associated aHUS, presumably triggered by SARS-CoV-2 infection during the second wave of the pandemic in June-July 2021. Three patients presented as relapse after a period of disease quiescence for 2-6 years. Given that we observe a seasonal predilection of patients with aHUS that peaks between the months of December and March [4], the increase in number of patients in June-July was unusual (Fig. 1). All patients had a preceding febrile illness 8-21 days prior to aHUS and showed high levels of SARS-CoV-2 antibodies with no evidence of any other infection. Daily plasma exchanges and use of immunosuppressive medications were associated with hematological remission, decline of anti-FH antibodies, and recovery of kidney function in 4 patients.

HUS is reported to be precipitated by several viral infections, including influenza A, human immunodeficiency virus, and norovirus [18]. Recently, patients with pathogenic or likely pathogenic variants in $C D 46$ [8], $C 3$ [7], and $C F H$ [6] were reported to present with aHUS, following mild SARS-CoV-2 infection. Two children with severe SARS-CoV-2 infection and HUS were also reported. Mahajan et al. reported a 14-year-old girl with severe COVID-19, cytokine storm, myocarditis, and HUS 
Table 1 Characteristics of patients with atypical hemolytic uremic syndrome associated with severe acute respiratory syndrome coronavirus 2 (SARS-CoV-2) infection

\begin{tabular}{|c|c|c|c|c|c|}
\hline Patient & 1 & 2 & 3 & 4 & 5 \\
\hline Age; sex & 4 years; boy & 12 years; boy & 13 years; boy & 7 years; boy & 10 years; girl \\
\hline Presentation & June 2021 & June 2021 & June 2021 & June 2021 & July 2021 \\
\hline Prodromal symptoms ${ }^{\mathrm{a}}$ & Fever 21 days prior & Fever 10 days prior & Fever 8 days prior & Fever 10 days prior & Fever 10 days prior \\
\hline Presenting features & $\begin{array}{l}\text { Anasarca, pallor, stage } \\
2 \text { hypertension }\end{array}$ & $\begin{array}{l}\text { Abdominal pain, } \\
\text { vomiting }\end{array}$ & $\begin{array}{l}\text { Abdominal pain, } \\
\text { vomiting, stage } 2 \\
\text { hypertension }\end{array}$ & $\begin{array}{l}\text { Abdominal pain, } \\
\text { oliguria, stage } 2 \\
\text { hypertension }\end{array}$ & $\begin{array}{l}\text { Oliguria, pallor, stage } 2 \\
\text { hypertension }\end{array}$ \\
\hline $\begin{array}{l}\text { Presentation as } \\
\text { relapse; months } \\
\text { from onset }\end{array}$ & No & Yes; 78 months & Yes; 85 months & Yes; 25 months & No \\
\hline $\begin{array}{l}\text { Hemoglobin g/dL; } \\
\text { schistocytes \%; } \\
\text { LDH IU/L; platelets } \\
/ \mu \mathrm{L}\end{array}$ & $3.5 ; 6 ; 1271 ; 120,000$ & $8.3 ; 3 ; 1573 ; 55,000$ & $6.9 ; 5 ; 1072 ; 60,000$ & $4.8 ; 6 ; 1100 ; 35,000$ & $5.8 ; 2 ; 1105 ; 32,000$ \\
\hline $\begin{array}{l}\text { Peak creatinine, mg/ } \\
\text { dL }\end{array}$ & 1.3 & 2.4 & 3.1 & 3.6 & 7.6 \\
\hline Serum C3, mg/dL & 84 & 52 & 48 & 69 & 64 \\
\hline $\mathrm{sC} 5 \mathrm{~b}-9, \mathrm{ng} / \mathrm{ml}$ & 4220.3 & Not done & 1179.9 & 1344.9 & 2900.3 \\
\hline $\begin{array}{l}\text { Anti-factor } \mathrm{H} \text { anti- } \\
\text { body, } \mathrm{AU} / \mathrm{mL}\end{array}$ & 13,304 & 2300 & 1580 & 1785 & 5036 \\
\hline $\begin{array}{l}\text { SARS-CoV-2 RT- } \\
\text { PCR; antibody } \\
(\mathrm{COI})^{\mathrm{b}}\end{array}$ & Negative; 47.1 & Positive; 55.6 & Negative; 135.8 & Negative; 27.3 & Negative; 10 \\
\hline $\begin{array}{l}\text { Exome sequencing, } \\
\text { MLPA }^{\mathrm{c}}\end{array}$ & Not done & $\begin{array}{l}\text { Homozygous } C F H R 1 \\
\text { deletion }\end{array}$ & $\begin{array}{l}\text { Homozygous } C F H R 1 \\
\text { deletion }\end{array}$ & $\begin{array}{l}\text { Homozygous } C F H R 1 \\
\text { deletion }\end{array}$ & Not done \\
\hline $\begin{array}{l}\text { Duration of plasma } \\
\text { exchange, days }\end{array}$ & 17 & 15 & 15 & 20 & 15 \\
\hline Medications & $\begin{array}{l}\text { IV cyclophosphamide, } \\
\text { prednisone }\end{array}$ & $\begin{array}{l}\text { Mycophenolate } \\
\text { mofetil, prednisone }\end{array}$ & $\begin{array}{l}\text { Mycophenolate } \\
\text { mofetil, prednisone }\end{array}$ & $\begin{array}{l}\text { Mycophenolate } \\
\text { mofetil, prednisone }\end{array}$ & $\begin{array}{l}\text { IV cyclophosphamide, } \\
\text { prednisone }\end{array}$ \\
\hline Duration of dialysis & 2 days & 3 days & 3 days & 7 days & 12 weeks, ongoing \\
\hline Follow-up & 4.4 months & 4.3 months & 3.9 months & 4.7 months & 2.8 months \\
\hline $\mathrm{eGFR} \mathrm{ml} / \mathrm{min} / 1.73 \mathrm{~m}^{2}$ & 134 & 85 & 87 & 47 & On dialysis \\
\hline $\begin{array}{l}\text { Antihypertensive } \\
\text { agents } \\
\text { Urine protein }\end{array}$ & $\begin{array}{l}1 \\
1+\end{array}$ & $\begin{array}{l}2 \\
1+\end{array}$ & $\begin{array}{l}3 \\
3+\end{array}$ & $\begin{array}{l}1 \\
3+\end{array}$ & $\begin{array}{l}2 \\
2+\end{array}$ \\
\hline
\end{tabular}

Normal range of serum C3>90 mg/dl; anti-FH antibody < 150 arbitrary units (AU)/l; median sC5b-9 195.3 (151.1-292.5) ng/ml in healthy controls [4]

${ }^{\mathrm{a}}$ Lack of respiratory symptoms of SARS-CoV-2 infection

${ }^{\mathrm{b}} \mathrm{IgG}$ and IgM total antibody detected by chemiluminescence immunoassay (normal $<1$ cut-off index, COI)

${ }^{\mathrm{c}}$ Variants in $C F H, C F I, C F B, C 3, C D 46, C F H R 1-5, D G K E$, THBD, ADAMTS13, and PLG prioritized; copy number variations in CFHR 1-5

$e G F R$ Estimated glomerular filtration rate, $L D H$ lactate dehydrogenase, $M L P A$ multiplex ligation-dependent probe amplification, $R T-P C R$ reverse transcriptase polymerase chain reaction, $s C 5 b-9$ soluble terminal complement complex

[19]. The second patient was a 16-month-old boy who presented with diabetes mellitus and aHUS after severe SARS-CoV-2 infection [20]. Both patients showed satisfactory response to therapy with eculizumab. Atypical HUS triggered by mild SARS-CoV-2 infection was reported in 2 adults, each with a pathogenic variant in $\mathrm{CFI}$ and an at-risk $\mathrm{CFH}-\mathrm{H} 3$ haplotype, who were additionally found to have anti-FH antibodies [15]. A homozygous CFHRI deletion was not found in these patients, in contrast to its characteristic association with anti-FH antibodies in $71.4-92.3 \%$ and $88.2 \%$ patients in Caucasian [21] and Indian [3] cohorts, respectively. The present study confirms the genetic association of anti-FH antibodies with homozygous $C F H R I$ deletion since it was found in all 3 patients who were tested. The present report adds to the pediatric literature on aHUS triggered by mild SARSCoV-2 infection, including the association with anti-FH antibodies. 
The mechanism for generation of anti-FH antibodies is incompletely understood. Their occurrence chiefly in schoolage children corresponding to peak incidence of common infections and winter predilection favors an infectious trigger [3]. Bhattacharjee et al. identified an anti-FH antibody epitope cluster within the short consensus repeat (SCR) 20 of $\mathrm{FH}$, where certain proteins synthesized by pathogens bind as part of an immune evasion strategy [22, 23]. The authors proposed that binding of microbial proteins to SCR20 induces a conformation change and generates a neoepitope that is similar to FHR1, which results in an autoimmune response in patients with $C F H R I$ deficiency [22]. While it is not clear if SARS-CoV-2 binds to FH, in vitro studies show that spike proteins of SARS-CoV-2 might competitively block cell-surface binding of FH [13], and complement dependent killing induced by the spike protein is mitigated by the addition of FH [24]. Several studies also suggest activation of the alternative complement pathway in the setting of COVID-19 [12, 24]. Apart from anti-FH antibodies, these factors might have had an additional role in causing endothelial injury in the current patients.

Since aHUS manifested following the recovery of SARSCOV-2 infection, specific immunosuppressive therapy could be initiated in our patients. A previous report from this center showed mild features of SARS-CoV-2 infection in children with chronic kidney disease including those receiving immunosuppression [25]. Therefore, in the absence of moderate to severe features of SARS-CoV-2 infection, patients with anti-FH associated aHUS may safely receive standard immunosuppressive therapy that is initiated when viral loads become undetectable. Brief therapy with eculizumab might be considered during acute infection when immunosuppressive therapy appears contraindicated.

About 15-20\% patients with anti-FH associated aHUS relapse, usually within the first 2 years of the illness [4]. In our nationwide database of 436 patents, relapses beyond 2 years were rare, and seen in $~ 5 \%$ patients [4]. On the other hand, 3 of our 5 patients had relapse of aHUS associated with high titer anti-FH antibodies, following prolonged remission for 2-6 years. The temporal sequence of a febrile illness with demonstration of infection by RT-PCR in 1 patient and by high anti-SARS-CoV-2 antibody titers in all suggests that infection with SARS-CoV-2 might be the trigger for occurrence of anti-FH associated aHUS, including the patients with late relapse. The seroprevalence of SARSCoV-2 infection in Delhi was 25\% in October 2020, which increased to $61-74 \%$ following the second COVID-19 wave $[26,27]$. While it is possible that the association of aHUS with COVID-19 might be a coincidence, all 5 patients were clustered within a few weeks during summer and followed the peak of the pandemic in Delhi. We suggest increased vigilance for SARS-CoV-2 infection triggered occurrence of anti-FH associated HUS, including in patients with quiescent disease for prolonged periods. Prompt diagnosis and appropriate therapy are associated with satisfactory kidney outcomes.

Supplementary Information The online version contains supplementary material available at https://doi.org/10.1007/s00467-021-05390-4.

Funding This study was funded by the Indian Council of Medical Research [Advanced Centre for Research in Pediatric Kidney Diseases; 5/7/1090/2013-RHN].

\section{Declarations}

Conflict of interest The authors declare no competing interests.

\section{References}

1. Fakhouri F, Zuber J, Fremeaux-Bacchi V, Loirat C (2017) Haemolytic uraemic syndrome. Lancet 390:681-696

2. Schaefer F, Ardissino G, Ariceta G, Fakhouri F, Scully M, Isbel N, Lommele A, Kupelian V, Gasteyger C, Greenbaum LA, Johnson S, Ogawa M, Licht C, Vande Walle J, Fremeaux-Bacchi V, Global aHUS Registry, (2018) Clinical and genetic predictors of atypical hemolytic uremic syndrome phenotype and outcome. Kidney Int 94:408-418

3. Sinha A, Gulati A, Saini S, Blanc C, Gupta A, Gurjar BS, Saini H, Kotresh ST, Ali U, Bhatia D, Ohri A, Kumar M, Agarwal I, Gulati S, Anand K, Vijayakumar M, Sinha R, Sethi S, Salmona M, George A, Bal V, Singh G, Dinda AK, Hari P, Rath S, DragonDurey MA, Bagga A, Indian HUS Registry (2014) Prompt plasma exchanges and immunosuppressive treatment improves the outcomes of anti-factor $\mathrm{H}$ autoantibody-associated hemolytic uremic syndrome in children. Kidney Int 85:1151-1160

4. Puraswani M, Khandelwal P, Saini H, Saini S, Gurjar BS, Sinha A, Shende RP, Maiti TK, Singh AK, Kanga U, Ali U, Agarwal I, Anand K, Prasad N, Rajendran P, Sinha R, Vasudevan A, Saxena A, Agarwal S, Hari P, Sahu A, Rath S, Bagga A (2019) Clinical and immunological profile of anti-factor $\mathrm{H}$ antibody associated atypical hemolytic uremic syndrome: a Nationwide Database. Front Immunol 10:1282

5. Togarsimalemath SK, Si-Mohammed A, Puraswani M, Gupta A, Vabret A, Liguori S, Mariani-Kurkdjian P, Bagga A, DragonDurey MA (2018) Gastrointestinal pathogens in anti-FH antibody positive and negative hemolytic uremic syndrome. Pediatr Res $84: 118-124$

6. Kaufeld J, Reinhardt M, Schroder C, Brasen JH, Wiech T, Brylka P, Khaled A, Bergmann C, Haller H, Gackler A, Schmidt BMW (2021) Atypical HUS triggered by infection with SARS-CoV2. Kidney Int Rep 6:2709-2712

7. Mat O, Ghisdal L, Massart A, Aydin S, Goubella A, Blankoff N, Gankam F, Debelle F, Mat Q (2021) Kidney thrombotic microangiopathy after COVID-19 associated with C3 gene mutation. Kidney Int Rep 6:1732-1737

8. Ville S, Le Bot S, Chapelet-Debout A, Blancho G, FremeauxBacchi V, Deltombe C, Fakhouri F (2021) Atypical HUS relapse triggered by COVID-19. Kidney Int 99:267-268

9. Tiwari NR, Phatak S, Sharma VR, Agarwal SK (2021) COVID-19 and thrombotic microangiopathies. Thromb Res 202:191-198

10. Diorio C, McNerney KO, Lambert M, Paessler M, Anderson EM, Henrickson SE, Chase J, Liebling EJ, Burudpakdee C, Lee JH, Balamuth FB, Blatz AM, Chiotos K, Fitzgerald JC, Giglia TM, Gollomp K, Odom John AR, Jasen C, Leng T, Petrosa W, Vella 
LA, Witmer C, Sullivan KE, Laskin BL, Hensley SE, Bassiri H, Behrens EM, Teachey DT (2020) Evidence of thrombotic microangiopathy in children with SARS-CoV-2 across the spectrum of clinical presentations. Blood Adv 4:6051-6063

11. Carvelli J, Demaria O, Vely F, Batista L, Chouaki Benmansour N, Fares J, Carpentier S, Thibult ML, Morel A, Remark R, Andre P, Represa A, Piperoglou C; Explore COVID-19 IPH group; Explore COVID-19 Marseille Immunopole group; Cordier PY, Le Dault E, Guervilly C, Simeone P, Gainnier M, Morel Y, Ebbo M, Schleinitz N, Vivier E (2020) Association of COVID-19 inflammation with activation of the C5a-C5aR1 axis. Nature 588:146-150

12. Ma L, Sahu SK, Cano M, Kuppuswamy V, Bajwa J, McPhatter J, Pine A, Meizlish M, Goshua G, Chang CH, Zhang H, Price C, Bahel P, Rinder H, Lei T, Day A, Reynolds D, Wu X, Schriefer R, Rauseo AM, Goss CW, O'Halloran JA, Presti RM, Kim AH, Gelman AE, Cruz CD, Lee AI, Mudd P, Chun HJ, Atkinson JP, Kulkarni HS (2021) Increased complement activation is a distinctive feature of severe SARS-CoV-2 infection. bioRxiv Preprint. https://doi.org/10.1101/2021.02.22.432177

13. Yu J, Gerber GF, Chen H, Yuan X, Chaturvedi S, Braunstein EM, Brodsky RA (2021) Complement dysregulation is associated with severe COVID-19 illness. Haematologica. https://doi.org/10.3324/ haematol.2021.279155

14. Galeotti C, Bayry J (2020) Autoimmune and inflammatory diseases following COVID-19. Nat Rev Rheumatol 16:413-414

15. El-Sissy C, Saldman A, Zanetta G, Vieira-Martins P, Poulain C, Cauchois R, Kaplanski G, Venetz JP, Bobot M, Dobosziewicz H, Daniel L, Koubi M, Sadallah S, Rotman S, Mousson C, Pascual M, Fremeaux-Bacchi V, Fakhouri F (2021) COVID-19 as a potential trigger of complement-mediated atypical HUS. Blood. https:// doi.org/10.1182/blood.2021012752

16. Bagga A, Khandelwal P, Mishra K, Thergaonkar R, Vasudevan A, Sharma J, Patnaik SK, Sinha A, Sethi S, Hari P, Dragon-Durey MA, Indian Society of Pediatric Nephrology (2019) Hemolytic uremic syndrome in a developing country: consensus guidelines. Pediatr Nephrol 34:1465-1482

17. Khandelwal P, Faruq M, Puraswani M, Sinha A, Bagga A (2018) Coexisting variations in complement regulatory genes increase risk of relapse in anti-Factor $\mathrm{H}$ antibody associated atypical hemolytic uremic syndrome. American Society of Nephrology Kidney Week - Abstract Details. https://www.asn-online.org/education/ kidneyweek/2018/program-abstract. aspx ? controlId=3024369. Accessed 8 October 2021

18. Lopes da Silva R (2011) Viral-associated thrombotic microangiopathies. Hematol Oncol Stem Cell Ther 4:51-59
19. Mahajan R, Lipton M, Broglie L, Jain NG, Uy NS (2020) Eculizumab treatment for renal failure in a pediatric patient with COVID-19. J Nephrol 33:1373-1376

20. Alizadeh F, O'Halloran A, Alghamdi A, Chen C, Trissal M, Traum A, DeCourcey D (2021) Toddler with new onset diabetes and atypical hemolytic-uremic syndrome in the setting of COVID19. Pediatrics 147:e2020016774

21. Durey MA, Sinha A, Togarsimalemath SK, Bagga A (2016) Anti-complement-factor $\mathrm{H}$-associated glomerulopathies. Nat Rev Nephrol 12:563-578

22. Bhattacharjee A, Reuter S, Trojnar E, Kolodziejczyk R, Seeberger H, Hyvarinen S, Uzonyi B, Szilagyi A, Prohaszka Z, Goldman A, Jozsi M, Jokiranta TS (2015) The major autoantibody epitope on factor $\mathrm{H}$ in atypical hemolytic uremic syndrome is structurally different from its homologous site in factor H-related protein 1, supporting a novel model for induction of autoimmunity in this disease. J Biol Chem 290:9500-9510

23. Meri T, Amdahl H, Lehtinen MJ, Hyvarinen S, McDowell JV, Bhattacharjee A, Meri S, Marconi R, Goldman A, Jokiranta TS (2013) Microbes bind complement inhibitor factor $\mathrm{H}$ via a common site. PLoS Pathog 9:e1003308

24. Yu J, Yuan X, Chen H, Chaturvedi S, Braunstein EM, Brodsky RA (2020) Direct activation of the alternative complement pathway by SARS-CoV-2 spike proteins is blocked by factor $\mathrm{D}$ inhibition. Blood 136:2080-2089

25. Krishnasamy S, Mantan M, Mishra K, Kapoor K, Brijwal M, Kumar M, Sharma S, Swarnim S, Gaind R, Khandelwal P, Hari P, Sinha A, Bagga A (2021) SARS-CoV-2 infection in children with chronic kidney disease. Pediatr Nephrol. https://doi.org/10. 1007/s00467-021-05218-1

26. Sharma N, Sharma P, Basu S, Saxena S, Chawla R, Dushyant K, Mundeja N, Marak Z, Singh S, Singh G, Rustagi R (2021) The seroprevalence of severe acute respiratory syndrome coronavirus 2 in Delhi, India: a repeated population-based seroepidemiological study. Trans R Soc Trop Med Hyg. https://doi.org/10.1093/trstmh/ trab109

27. Misra P, Kant S, Guleria R, Rai SK; WHO Unity Seroprevalence study team of AIIMS (2021) Serological prevalence of SARSCoV-2 antibody among children and young age (between age 2-17 years) group in India: an interim result from a large multi-centric population-based seroepidemiological study. medRxiv Preprint. https://doi.org/10.1101/2021.06.15.21258880

Publisher's Note Springer Nature remains neutral with regard to jurisdictional claims in published maps and institutional affiliations. 